\title{
RELIABILITY MODELLING ON TWO-DIMENSIONAL LIFE DATA USING BIVARIATE WEIBULL DISTRIBUTION:WITH CASE STUDY OF TRUCK IN MINES
}

\section{MODELOWANIE NIEZAWODNOŚCIOWE DWUWYMIAROWYCH DANYCH DOTYCZĄCYCH OKRESU EKSPLOATACJ Z WYKORZYSTANIEM DWUWYMIAROWEGO ROZKŁADU WEIBULLA. Z BADAŃ NAD WYWROTKAMI KOPALNIANYMI}

\begin{abstract}
An engineering system can exhibit two- or multi-dimensions in its lifetime. As the classical univariate distribution cannot model this multi-dimensional characteristic, it is necessary to extend it to multivariate distribution in order to capture the multi-dimensional characteristics. This paper proposes a bivariate Weibull distribution that combines two classical Weibull models by a common exponent. The common exponent can represent the correlation between the two dimensions. A ratio likelihood test is proposed to test the significance of the correlation between the two dimensions. To solve the parameter estimation problem, this paper suggests a Bayesian method. Moreover, a goodness of fit test method is developed to visually check the fitness of the model. A case study considering mining trucks is presented to apply the bivariate Weibull distribution to model the two-dimensional life data.
\end{abstract}

Keywords: bivariate Weibull; life data; reliability modelling; Bayesian method; mining truck.

\begin{abstract}
Systemy inżynieryjne można charakteryzować za pomoca dwóch lub więcej wymiarów dotyczacych okresu ich eksploatacji (np. przebieg i czas pracy pojazdu). Ponieważ klasyczny rozktad jednowymiarowy nie wystarcza do zamodelowania tej wielowymiarowej charakterystyki, konieczne jest wykorzystanie rozkładu wielowymiarowego, który pozwala uchwycić wielowymiarowość cyklu życia systemu. W artykule zaproponowano dwuwymiarowy rozktad Weibulla, który taczy w sobie dwa klasyczne modele Weibulla za pomoca wspólnego wykładnika. Wspólny wykładnik może reprezentować korelację między dwoma wymiarami. Zaproponowano test ilorazu wiarygodności, który umożliwia badanie istotności korelacji pomiędzy dwoma wymiarami. Do rozwiazania problemu estymacji parametrów zastosowano metodę bayesowska. Ponadto opracowano metodę badania dopasowania modelu do danych empirycznych stużaca do wizualizacji dopasowania modelu. Przedstawiono studium przypadku dotyczace wywrotek kopalnianych, w którym dwuwymiarowy rozkład Weibulla zastosowano do modelowania dwuwymiarowych danych dotyczacych okresu eksploatacji tych pojazdów.
\end{abstract}

Stowa kluczowe: dwuwymiarowy rozkład Weibulla; dane z okresu eksploatacji; modelowanie niezawodności; metoda Bayesa; wywrotka kopalniana.

\section{Introduction}

It is not rare for engineering systems exhibiting binary- or even multi-dimensional lifetimes. The life of an airplane can be described by both calendar time and the total flight hours; the life of rail track life can be described according to both age and the total gross load it has carried [2], while an automobile's usage also corresponds with calendar time and distance travelled [12]. Binary-dimensional or multi-dimensional failure times are also practical when a system comprises several dependent components. For example, for the railway bogie, the failures of a wheel, an axle or a spring are essentially dependent on each other. The reliability of the bogie should address the dependency of the load, torque or other mechanic measurement on each other. Each measurement is a dimension corresponding to the lifetime. Multi-dimensional distribution is also practical when a system has multiple dependent failure modes. Each failure mode corresponds one dimension in the lifetime.

Classic life-data analysis in reliability considers only one dimension $[4,24,26,28]$. A typical example is Weibull analysis, which considers time as the sole variate. The covariate-based model, such as the
Proportional Hazard Model (PHM), can accommodate multi-dimensional variates to some extend $[3,7,14,15]$. The main dimension, usually calendar time, is in the baseline function. The other dimensions are accommodated in the covariate function. However, covariates are not one dimension of the distribution. The PHM is essentially a one-dimensional model.

It is thus necessary to develop multivariate lifetime distribution model, applicable for reliability analysis. In the desired multi-dimensional model, each dimension of the lifetime is considered equal, instead of as covariate as in the PHM model. In order to apply the model to reliability analysis, the corresponding parameter estimation and goodness of fit test method should also be proposed. This paper is organized as follows: Section 2 presents the literature survey and discusses some properties of the bivariate Weibull model concerned with reliability. Section 3 presents the methods for parameter estimation and the reliability evaluation, while Section 4 discusses the case of the mining transportation truck and the application of the Bivariate Weibull model to the case. Finally, Section 5 presents the discussion and conclusion of the paper. 


\section{Bivariate Weibull model}

Weibull distribution can characterize an increasing, decreasing and constant failure rate. The desirable bivariate distribution is designated to retain this advantage.

\subsection{Bivariate Distribution Model}

Various state-of-the-art bivariate distributions have been developed. Copula models are some of them. The Copula model uses a copula function to connect two or more cumulative distribution functions [27]. For different Copula functions and cumulative distribution, there are the Gaussian Copula model, the Gumbel Copula model, the Frank Copula model, the Joe Copula model, etc. [8]. The Copula model can model the dependence of the multi-variant distribution and is especially suitable for mechanical system reliability analysis. However, Copula models require an explicit expression of the marginal distribution for each variate. For example, for the bivariate situation, suppose the marginal distribution is $u$ and $v$. The Gumbel Copula function is defined as:

$$
C(u, v ; \theta)=\exp \left\{-\left[(-\ln u)^{\frac{1}{\theta}}+(-\ln v)^{\frac{1}{\theta}}\right]^{\theta}\right\}
$$

The dependency of the two marginal distributions is contained in the Copula parameter $\theta$. In the univariate distribution, the exponential and Weibull distributions are intensively investigated. It is preferable to have a bivariate distribution of exponential or Weibull forms. The bivariate distribution is designated to inherit the good properties from the univariate exponential or Weibull distribution. For most exponential or Weibull distribution-based bivariate distributions, in general, the cumulative density function of the bivariate distribution can be written in the form:

$$
R(t, s)=\exp [-f(t, s)]
$$

State-of-the-art models, with the bivariate Marshall-Olkin model being one of the most famous among them, differ in the definition of the function $f(t, s)$ [23]. The bivariate Marshall-Olkin model considers the two variates to be exponentially distributed. The two variates are competing to fail. The Marshall-Olkin takes the form:

$$
R(t, s)=\exp \left[-\lambda_{1} \mathrm{t}-\lambda_{2} \mathrm{~s}-\lambda_{0} \operatorname{Max}(\mathrm{t}, \mathrm{s})\right]
$$

Hanagal (1996) extended Model (3) to bivariate or multivariate Weibull distribution by replacing the exponential distribution of (3) by Weibull distribution [6]:

$$
R(t, s)=\exp \left[-\alpha_{1} t^{\mathrm{c}}-\alpha_{2} s^{\mathrm{c}}-\alpha_{3} \operatorname{Max}(t, s)^{\mathrm{c}}\right]
$$

Ryu (1993) developed another bivariate Weibull distribution that extends the classical bivariate Marshall-Olkin. The model is as follows [32]:

$R\left(t_{1}, t_{2}\right)=\left\{\begin{array}{l}\exp \left[-\alpha_{1} t_{1}^{\beta_{1}}-\alpha_{12} t_{2}-\alpha_{2} t_{2}^{\beta_{2}}+\frac{\alpha_{12}}{\gamma_{2}}\left(1-e^{-\gamma_{2}\left(t_{2}-t_{1}\right)}\right)+\frac{\alpha_{12}}{\gamma_{2}-\gamma_{1}}\left(e^{-\gamma_{2}\left(t_{2}-t_{1}\right)}-e^{-\gamma_{1} t_{1}-\gamma_{2} t_{2}}\right)\right] ; t_{1} \leq t_{2} \\ \exp \left[-\alpha_{1} t_{1}^{\beta_{1}}-\alpha_{12} t_{1}-\alpha_{2} t_{2}^{\beta_{2}}+\frac{\alpha_{12}}{\gamma_{1}}\left(1-e^{-\gamma_{2}\left(t_{2}-t_{1}\right)}\right)+\frac{\alpha_{12}}{\gamma_{2}-\gamma_{1}}\left(e^{-\gamma_{1}\left(t_{1}-t_{2}\right)}-e^{-\gamma_{1} t_{1}-\gamma_{2} t_{2}}\right)\right] ; t_{1}>t_{2}\end{array}\right.$

This model is much more complex than the model developed by
Hanagal (1996), which complicates the parameter estimation. Other available models such as the Nataf model, the 2D Nagao-Kadoya-Rice model and the Placket model are derived from univariate Weibull distribution [18]. These models are simpler than (5) but still have complex analytical expressions. We prefer the simple model with fewer parameters and a simple reliability function or probability density function. Roy (1994) developed another bivariate Weibull distribution with a simpler form of reliability function [30]:

$$
R(t, s)=\exp \left[-\alpha_{1} t^{\beta_{1}}-\alpha_{2} s^{\beta_{2}}-\alpha_{3} t^{\beta_{1}} s^{\beta_{2}}\right]
$$

In that model, the dependence of two variates is described by the term $\alpha_{3} x^{\beta_{1}} y^{\beta_{2}}$. Hougaard (1986), Lu and Bhattacharyya (1990) and Joy (1998) developed a bivariate Weibull model by combining the two bivariates by means of a common exponent [10, 17, 20,31,34]. This model is simple, and it can be derived from physical model:

$$
\begin{aligned}
& \frac{\partial h(s, t)}{\partial t}=\gamma^{2} \alpha_{1}^{-2} \beta_{1}\left(\beta_{1}-1\right)\left(\frac{t}{\alpha_{1}}\right)^{\beta_{1}-2} \alpha_{2}^{-1} \beta_{2}\left(\frac{s}{\alpha_{2}}\right)^{\beta_{2}-1}\left[\left(\frac{t}{\alpha_{1}}\right)^{\beta_{1}}+\left(s / \alpha_{2}\right)^{\beta_{2}}\right]^{\gamma-2}\left\{\frac{1}{\gamma}-1+\left[\left(\frac{t}{\alpha_{1}}\right)^{\beta_{1}}+\left(s / \alpha_{2}\right)^{\beta_{2}}\right]\right\}+ \\
& \gamma^{2} \alpha_{1}^{-1} \beta_{1}\left(\frac{t}{\alpha_{1}}\right)^{\beta_{1}-1} \alpha_{2}^{-1} \beta_{2}\left(\frac{s}{\alpha_{2}}\right)^{\beta_{2}-1}\left\{\left(\frac{1}{\gamma}-1\right)(\gamma-2) \alpha_{1}^{-1} \beta_{1}\left(\frac{t}{\alpha_{1}}\right)^{\beta_{1}-1}\left[\left(\frac{t}{\alpha_{1}}\right)^{\beta_{1}}+\left(s / \alpha_{2}\right)^{\beta_{2}}\right]^{\gamma-3}+(2 \gamma-2) \alpha_{1}^{-1} \beta_{1}\left(\frac{t}{\alpha_{1}}\right)^{\beta_{1}-1}\left[\left(t / \alpha_{1}\right)^{\beta_{1}}+\left(s / \alpha_{2}\right)^{\beta_{2}}\right]^{2 \gamma-3}\right\}
\end{aligned}
$$

This paper follows Model (7), but with a slight modification. This bivariate Weibull model considered by this paper is of this form:

$$
R(t, s)=\exp \left[-\left(\alpha_{1} t^{\beta_{1}}+\alpha_{2} s^{\beta_{2}}\right)^{\gamma}\right] .
$$

The same model as (8) is also shown in [10, 17]. The model is the simplest state-of-the-art model for bivariate Weibull distribution derived from univariate Weibull distribution. This paper uses this model due to its simplicity.

\subsection{Bivariate hazard function}

In the case of a univariate case, for example where only time is under consideration, the hazard function describes the conditional probability that a system will fail per time unit, given that the system has survived until time t. Provided the failure distribution function is first-order continuous, the hazard function can be defined as:

$$
r(t)=\frac{\lim _{\Delta t \rightarrow 0} \frac{F(t+\Delta t)-F(t)}{\Delta t}}{R(t)}=\frac{f(t)}{R(t)}
$$

Extending (9), we can derive the hazard function of the bivariate case as:

$$
\mathrm{r}(t, s)=\frac{\lim _{\substack{\Delta t \rightarrow 0 \\ \Delta s \rightarrow 0}} \frac{F(t+\Delta t, s+\Delta s)-F(t, s)}{\Delta t \Delta s}}{R(t, s)}=\frac{\partial F(t, s) / \partial t+\partial F(t, s) / \partial s}{R(t, s)}
$$

This formula implies the bivariate failure rate and its distribution function can be converted from each other. For the univariate case, a simple and flexible hazard function is of the power form $\left.\Lambda(t)=\int r(t) d t=(t / \alpha)^{\beta-1}\right)$. This is the hazard function of the two-parameter Weibull distribution. This form can describe a monotonically increasing, decreasing and constant hazard function. This monotonicity 
describes the physical characteristics of the system. The desired hazard function of model (8) for bivariate-dimensional distribution also retains this advantage. This cumulative hazard function of model (8) is a combination of the cumulative hazard function of the two variates:

$$
\mathrm{B}=\left(t / \alpha_{1}\right)^{\beta_{1}}+\left(s / \alpha_{2}\right)^{\beta_{2}}
$$

where $\gamma>0 ; \alpha_{1}, \alpha_{2} \geq 0 ; \beta_{1}, \beta_{2} \geq 0 ; \alpha_{1}, \alpha_{2}, \beta_{1}, \beta_{2}, \gamma \in R$, and $\alpha_{1}, \alpha_{2}$ cannot both be zero. This condition ensures the $\lim _{t \rightarrow \infty} \mathrm{r}(\mathrm{t}, \mathrm{s})=+\infty$. Equation $(11)$ $s \rightarrow \infty$

is the desired cumulative hazard function of binary Weibull distribution. The cumulative hazard function is linear when all shape parameters and $\gamma$ are equal to 1 . For simplicity of notation, we let $\mathrm{B}=\left(t / \alpha_{1}\right)^{\beta_{1}}+\left(s / \alpha_{2}\right)^{\beta_{2}}$.

This (11) is similar but simplifies the cumulative hazard function described by Lu and Hougaard [9-11, 20]. This model implicitly assumes the two variates $s$ and $t$ are influenced by the unknown common factor $\gamma$ The variates $t$ and $s$ are independent only when $\gamma=1$. By binomial series expansion, Equation (11) expands into a series as:

$$
\Lambda(t, s)=\left(t / \alpha_{1}\right)^{\beta_{1}}+\gamma\left(s / \alpha_{2}\right)^{\beta_{2}}+\frac{\gamma(\gamma-1)}{2 !}\left(t / \alpha_{1}\right)^{\beta_{1}} \cdot\left(s / \alpha_{2}\right)^{\beta_{2}}+\frac{\gamma(\gamma-1)(\gamma-2)}{3 !} \frac{\left(\left(s / \alpha_{2}\right)^{\beta_{2}}\right)^{3}}{\left(\left(t / \alpha_{1}\right)^{\beta_{1}}\right)^{2}} \ldots
$$

when $\left(s / \alpha_{2}\right)^{\beta_{2}}<\left(t / \alpha_{1}\right)^{\beta_{1}}$. Equation (12) reveals that Model (11) degenerates into a linear model where variates $s$ and $t$ are independent. Model (6) is also a special case of (11). Model (6) only considers the first three terms of (11). It is also revealed from (11) that, when $\gamma<1$, Model (11) is nonlinear and the interaction of $s$ and $t$ are considered.

The reliability function corresponding to hazard function (11) is $R=\exp [-\Lambda(t, s)]$. The corresponding probability density function (PDF) is:

$$
\begin{aligned}
f(s, t) & =\gamma^{2} \alpha_{1}^{-1} \beta_{1}\left(t / \alpha_{1}\right)^{\beta_{1}-1} \alpha_{2}^{-1} \beta_{2}\left(s / \alpha_{2}\right)^{\beta_{2}-1}\left[\left(t / \alpha_{1}\right)^{\beta_{1}}+\left(s / \alpha_{2}\right)^{\beta_{2}}\right]^{\gamma-2}\left\{1 / \gamma-1+\left[\left(t / \alpha_{1}\right)^{\beta_{1}}+\right.\right. \\
& \left.\left.+\left(s / \alpha_{2}\right)^{\beta_{2}}\right]^{\gamma}\right\} \exp \left(-\left[\left(t / \alpha_{1}\right)^{\beta_{1}}+\left(s / \alpha_{2}\right)^{\beta_{2}}\right]^{\gamma}\right)
\end{aligned}
$$

As $\gamma \in(0,1] \gamma \in(0,1]$, the $f(s, t) f(s, t)$ is positive, which ensures (13) is a legitimate PDF function. The corresponding hazard function is:

$$
h(s, t)=\frac{f(t)}{R(t)}=\gamma^{2} \alpha_{1}^{-1} \beta_{1}\left(t / \alpha_{1}\right)^{\beta_{1}-1} \alpha_{2}^{-1} \beta_{2}\left(s / \alpha_{2}\right)^{\beta_{2}-1}\left[\left(t / \alpha_{1}\right)^{\beta_{1}}+\left(s / \alpha_{2}\right)^{\beta_{2}}\right]^{\gamma-2}\left\{1 / \gamma-1+\left[\left(t / \alpha_{1}\right)^{\beta_{1}}+\left(s / \alpha_{2}\right)^{\beta_{2}}\right]^{\gamma}\right\}
$$

as:

$$
\begin{aligned}
& \frac{\partial h(s, t)}{\partial t}=\gamma^{2} \alpha_{1}^{-2} \beta_{1}\left(\beta_{1}-1\right)\left(\frac{t}{\alpha_{1}}\right)^{\beta_{1}-2} \alpha_{2}^{-1} \beta_{2}\left(\frac{s}{\alpha_{2}}\right)^{\beta_{2}-1}\left[\left(\frac{t}{\alpha_{1}}\right)^{\beta_{1}}+\left(s / \alpha_{2}\right)^{\beta_{2}}\right]^{\gamma-2}\left\{\frac{1}{\gamma}-1+\left[\left(\frac{t}{\alpha_{1}}\right)^{\beta_{1}}+\left(s / \alpha_{2}\right)^{\beta_{2}}\right]^{\gamma}\right\} \\
& \gamma^{2} \alpha_{1}^{-1} \beta_{1}\left(\frac{t}{\alpha_{1}}\right)^{\beta_{1}-1} \alpha_{2}^{-1} \beta_{2}\left(\frac{s}{\alpha_{2}}\right)^{\beta_{2}-1}\left\{\left(\frac{1}{\gamma}-1\right)(\gamma-2) \alpha_{1}^{-1} \beta_{1}\left(\frac{t}{\alpha_{1}}\right)^{\beta_{1}-1}\left[\left(\frac{t}{\alpha_{1}}\right)^{\beta_{1}}+\left(s / \alpha_{2}\right)^{\beta_{2}}\right]^{\gamma-3}+(2 \gamma-2) \alpha_{1}^{-1} \beta_{1}\left(\frac{t}{\alpha_{1}}\right)^{\beta_{1}-1}\left[\left(t / \alpha_{1}\right)^{\beta_{1}}+\left(s / \alpha_{2}\right)^{\beta_{2}}\right]^{2 \gamma}\right.
\end{aligned}
$$

as: $0<\gamma \leq 1$, when:

$$
\left\{\begin{array}{c}
\beta_{1}=1 ; \frac{\partial h(s, t)}{\partial t} \neq 0 \\
\beta_{1}>1 ; \frac{\partial h(s, t)}{\partial t} \text { is not monotonic } \\
0<\beta_{1}<1 ; \frac{\partial h(s, t)}{\partial t}<0
\end{array}\right.
$$


A similar situation is for $\frac{\partial h(s, t)}{\partial s}$. The (16) reveals a weakness of Model (8): the failure rate is not always monotonic. When $\beta_{1}=1$, the hazard function for the bivariate Weibull is not the constant. Some desired properties for the univariate Weibull has not retained in the multi-dimensional model.

\section{Parameter estimation of bivariate Weibull model}

The bivariate Weibull model should overcome the parameter estimation issue in order for it to be applied to reliability. This section firstly derives the likelihood function of the bivariate model. This likelihood function will be used for parameter estimation and for optimal model selection among various bivariate models.

\subsection{Likelihood function}

When observed failure data are given as pairwise $\left(s_{i}, t_{i}\right) i=1,2, .$. , the likelihood function corresponding to (13) is:

$$
L=\prod_{i=1}^{n} f\left(s_{i}, t_{i}\right)
$$

The marginal distributions are $R(s, 0)=\exp \left(-\left(s / \alpha_{1}\right)^{\gamma \beta_{1}}\right)$ and $R(0, t)=\exp \left(-\left(t / \alpha_{2}\right)^{\gamma \beta_{2}}\right)$, where the model have degenerated into two univariate Weibull distributions.

$$
\begin{aligned}
& \ln \mathrm{L}=n\left(-\ln \mathrm{a}_{1}-\ln \mathrm{a}_{2}+2 \operatorname{lng}+\ln \mathrm{b}_{1}+\ln \mathrm{b}_{2}\right)+\left(\mathrm{b}_{1}-1\right) \sum t_{i} / \mathrm{a}_{1} \\
& \quad+\left(\beta_{2}-1\right) \sum s_{i} / \alpha_{2}+(\gamma-2) \sum \ln \mathrm{B}_{i}+\sum \ln \left(1 / \gamma-1+\mathrm{B}_{i}^{\gamma}\right)-\sum \mathrm{B}_{i}^{\gamma}(18)
\end{aligned}
$$

The maximum likelihood estimate method can be used to estimate the parameters. There are no explicit analytical solutions by maximizing (18). One has to resort to a numerical method to find a solution. This numerical computation is heavy to find the solution by maximizing (18). However, the computation can be simplified, as the likelihood function (17) has a special property: the maximum likelihood estimator of $\gamma$ is unique when $B_{i}$ is known. The proof is shown as follows. The computation can be simplified if the parameters in the two individual Weibull distributions are known.

Theory 1: The likelihood function in (17) has a unique global maximum when $\mathrm{B}_{i} \geq 0$.

Proof: Rewrite (11) as B and we consider the B as a variable. The PDF corresponding to Model (8) can then be written as $f(\mathrm{~B})=\gamma \mathrm{B}^{\gamma-1} \exp \left(-\mathrm{B}^{\gamma}\right)$. It is a continuous function for $\mathrm{B} \in \mathrm{R}$. A likelihood function can then be written as:

$$
\ln \mathrm{L}=\mathrm{f}(\gamma)=n \ln \gamma+(\gamma-1) \sum \ln \mathrm{B}_{i}-\sum \mathrm{B}_{i}^{\gamma} .
$$

The function is continuous and has a second derivative as:

$$
\frac{\partial^{2} \ln L}{\partial \gamma^{2}}=-\left[\frac{n}{\gamma^{2}}+\sum \mathrm{B}_{i}^{\gamma}\left(\ln \mathrm{B}_{i}\right)^{2}\right]
$$

Then $\frac{\partial^{2} \ln L}{\partial \gamma^{2}} \leq 0$ when $\mathrm{B}_{i} \geq 0$, i.e. the $\ln L$ is a concave function when $\mathrm{B}_{i} \geq 0$. The local maximum will be the global maximum. The maximum likelihood estimate obtained by setting the first derivative to zero has a unique and global solution. This property facilitates the parameter estimation. Once the $\mathrm{B}_{i}$ is known, one can find the optimal $\gamma$.

\subsection{Test the significance of correlation}

When $\gamma=1$, Model (8) degenerates to a classic competing model. The $\gamma$ contains the information about correction between the two variates $s, t$. The likelihood ratio test can be used to test the significance of $\gamma$. The hypothesis is:

$$
H_{0}: \gamma=1 ; H_{1}: \gamma \neq 1
$$

The statistics for test $T=\frac{L_{\gamma \neq 1}}{L_{\gamma=1}}$. The $H_{0}$ is accepted when the $\chi^{2}(1) \geq T$

The PDF of (8) for $\gamma=1$ degenerates into $f(s, t)=f(s) . f(t)$, i.e. two independent univariate Weibull distributions. The likelihood function is then $L_{\gamma=1}=\max L(s) \cdot \max L(t)$. The significance test of $\gamma$ can facilitate the parameter estimation. If $\gamma$ is significantly near to 1 , the two variates in (8) are considered as independent. One can hence estimate the parameters as univariate Weibull distributions for each dimension.

\subsection{Bayesian parameter estimation}

As there is no analytical solution to the parameter estimate problem for Model (8), using maximum likelihood estimate when the two variates are significantly correlated, only a numerical method is feasible. For this situation, alternatively, this paper proposes a Bayesian estimate method $[5,19,25]$. The Bayesian method considers the parameter as a random variable. The distribution of the random variable (prior distribution) should be specified. For the univariate Weibull model, when the shape parameter is known, Gamma distribution can be used as the prior distribution for the scale parameter [16]. However, practically, the shape parameter is unknown in a more general situation. This paper uses the general Gamma and Beta distribution as the prior distribution.

As $\alpha_{1}, \alpha_{2}, \beta_{1}, \beta_{2}>0$, this paper assumes their prior distributions follow Gamma distribution. The $\gamma$ is assumed to be Beta distribution since it is confined in $(0,1)$. The case with $\gamma=1$ can be considered separately. The full Bayesian expression is then:

$$
\begin{gathered}
\pi\left(\alpha_{1}, \alpha_{2}, \beta_{1}, \beta_{2}, \gamma \mid \text { Data }\right) \propto \\
L(\text { Data }) \times \frac{1}{\Gamma\left(a_{1}\right) b_{1}^{a_{1}}} \alpha_{1}^{a_{1}-1} e^{-\frac{\alpha_{1}}{b_{1}}} \times \frac{1}{\Gamma\left(a_{2}\right) b_{2}^{a_{2}}} \alpha_{1}^{a_{2}-1} e^{-\frac{\alpha_{2}}{b_{2}}} \times \\
\frac{1}{\Gamma\left(a_{3}\right) b_{3}^{a_{3}}} \beta_{1}^{a_{3}-1} e^{-\beta_{1} / b_{3}} \times \frac{1}{\Gamma\left(a_{4}\right) b_{4}^{a_{4}}} \beta_{2}^{a^{a^{-1}}} e^{-\beta_{2} / b_{4}} \times \frac{\Gamma\left(a_{5}\right)}{\Gamma\left(a_{5}\right) \Gamma\left(b_{5}\right)} \gamma^{a_{5}-1}(1-\gamma)^{b_{5}-1}
\end{gathered}
$$

The $a_{1}, b_{1}, a_{2}, b_{2}, a_{3}, b_{3}, a_{4}, b_{4}, a_{5}, b_{5}$ are hyper-parameters for the corresponding distribution. When there is no expert information or no knowledge regarding the hyper-parameters, the uninformative uni- 
form distribution can be used; that is the case in this paper. Alternatively, one can use Jeffreys' prior as prior distribution [1]. However, Jeffreys' prior requires the Fisher information matrix. For our model with five unknown parameters, the Fisher information matrix is complex. Therefore, Jeffreys' prior is not preferable. In order to obtain the posterior distribution of parameters, this papers uses the MCMC (Markov chain Monte Carlo) simulation method with Gibbs sampling [22]. The discussion on the computing method is ignored here, as it is not the main concern of this paper.

\subsection{Reliability evaluation using Bayesian method}

The reliability can be evaluated once the parameters in Model (8) are known. One advantage of the Bayesian method is that the distribution of the estimator is its posterior distribution. Reliability and its credible interval can be readily derived since each of the distributions of the parameters is known. The point reliability at time t, by integrating (8) and (22), is as follows:

$\mathrm{R}(t, s)=\int_{0}^{\infty} e^{\left(\left(t / \alpha_{1}\right)^{\beta_{1}}+\left(s / \alpha_{2}\right)^{\beta_{2}}\right)^{\gamma}} \pi\left(\alpha_{1}, \alpha_{2}, \beta_{1}, \beta_{2}, \gamma \mid\right.$ Data $) d \alpha_{1} d \beta_{1} d \alpha_{2} d \beta_{2} d \gamma$

The corresponding credible interval for $\mathrm{R}(t, s)$ at significance level $\alpha$ is:

$$
\begin{aligned}
& \int_{0}^{\theta_{L}} e^{\left(\left(t / \alpha_{1}\right)^{\beta_{1}}+\left(s / \alpha_{2}\right)^{\beta_{2}}\right)^{\gamma}} \pi\left(\alpha_{1}, \alpha_{2}, \beta_{1}, \beta_{2}, \gamma \mid \text { Data }\right) d \alpha_{1} d \beta_{1} d \alpha_{2} d \beta_{2} d \gamma=\alpha / 2 \\
& \int_{0}^{\theta_{U}} e^{\left(\left(t / \alpha_{1}\right)^{\beta_{1}}+\left(s / \alpha_{2}\right)^{\beta_{2}}\right)^{\gamma}} \pi\left(\alpha_{1}, \alpha_{2}, \beta_{1}, \beta_{2}, \gamma \mid \text { Data }\right) d \alpha_{1} d \beta_{1} d \alpha_{2} d \beta_{2} d \gamma=1-\alpha / 2
\end{aligned}
$$

where $\theta=f\left(\alpha_{1}, \beta_{1}, \alpha_{2}, \beta_{2}, \gamma\right)$. The lower and upper bound of $\mathrm{R}(t, s)$ given parameter $\theta$ is:

$$
\mathrm{R}(t, s)=\left[\inf \left(R\left(t, s ; \theta_{L}\right)\right), \sup \left(R\left(t, s ; \theta_{u}\right)\right)\right]
$$

It is hard to obtain the analytical expression of $\theta_{L}$ and $\theta_{U}$. The (25) can be derived using the MCMC simulation method. The MCMC method is a standard method to find the solution in Bayesian analysis. One can refer to [21] for detail.

\section{Case study}

The case study addresses the reliability analysis of trucks at Jajarm Bauxite Mine in Iran. Jajarm Bauxite Mine is an open-pit mine, where the ore rock and waste is hauled by truck from the mine to the allocated deposition places. In this mine, the ore rock is diasporic bauxite and the waste is flysch, which is characterized by the rhythmic alternations of sandstone and fine-grained layers. The fine-grained layers contain siltstone, silty shales, clay shales, and, rarely, limestone beds or an ophiolitic mass may be found close to its margins. Based on the percentage of diaspora, ore rock is divided into three groups: Hard Bauxite (HB), Kaolin Bauxite (KB) and Shale Bauxite (SB). Waste and ore deposition are located in different places, at varying distances from the mine. The waste rock and ore rock depots are around 4 and 15 kilometres outside the mine pit, respectively. The trucks transfer the ore rock during the day shift, and, during the night shift, they work on the waste rock. This mine is the biggest bauxite mine in Iran, at a length of 11 kilometres. It is divided into 12 different sections, each section working independently with its own allocated trucks. Currently, two types of trucks work in this mine: truck Type A and Type B. The capacity of Type A is 14 tons and of Type B is 35 tons. The truck

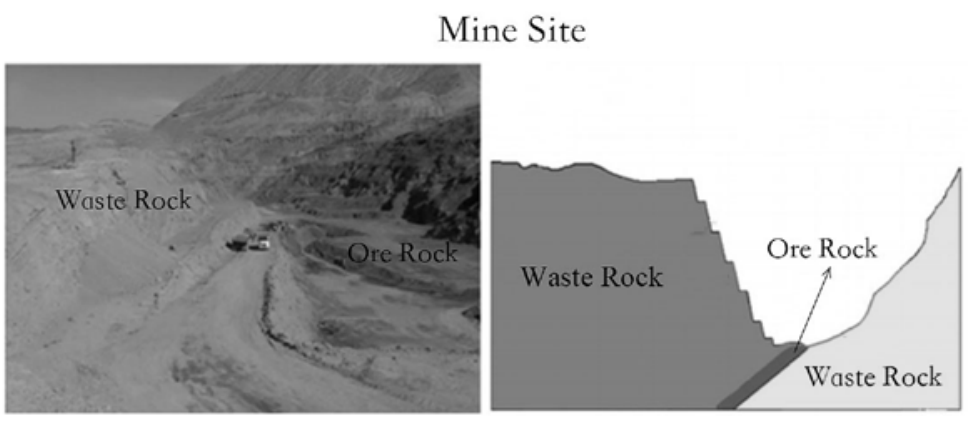

Fig. 1. Mining activities in Jajarm Bauxite Mines

drivers have, on average, 12 years' experience. The mine has its own repair shop, where all maintenance is carried out by mine employees. The mine follows the preventive maintenance plan recommended by the truck manufacturing company. Fig. 1 shows a picture and a geological section of Jajarm Bauxite Mine.

\subsection{Data description}

Data are collected from the maintenance database for two trucks. The database records the total tons carried by the trucks between two failure times. During operation, the trucks carry SB, KB, HB and waste. The travel distance from the original location to the destination varies for iron ore or waste, as they are located in different spots. This paper defines the product of tonnage and travelled distance in $\mathrm{km}$, abbreviated as Tons $\times \mathrm{kM}$, as the work load, as the failure depends on both the tonnage and the distance travelled. After sorting out the data, the total number of failures observed for each truck is 49 and 32, respectively. Table 1 shows all the Time To Failure (TTFs) and the workload.

\subsection{Fitting data to bivariate Weibull model}

Considering TTF as one dimension (variate) and the workload as another dimension (variate), the bivariate Weibull models are used as reliability models. In order to compare the performance, this paper uses three models as the bivariate Weibull models: the simple bivariate Weibull model, where the two dimensions are independent; the model (6) in Section 2; and the desired model (8) also in Section 2.

\subsubsection{Model 1: Simple bivariate Weibull model}

The first model uses the simple model of cumulative hazard function, assuming $\gamma=1$ for $\Lambda(t, s)=\left(\left(t / \alpha_{1}\right)^{\beta_{1}}+\left(s / \alpha_{2}\right)^{\beta_{2}}\right)^{\gamma}$. This implicitly assumes the two variates are independent of each other. We estimate the scale and shape parameters for the classical univariate Weibull distribution for each variate. The maximum likelihood method is used for each univariate Weibull distribution to estimate the parameters. The results are shown in Table 2.

\subsubsection{Model 2: Linear bivariate Weibull model}

Model (6) is also applied to analyse the data. In order to differentiate it from the other models, we name it the linear bivariate Weibull model. Let $\mathrm{t}$ in the bi-Weibull denote the calendar time and s denote the work load, Ton $\times \mathrm{kM}$. The probability density function for Model (6) is written as: 
Table 1. Failure Data Collected from Field for Truck 1 and Truck 2

\begin{tabular}{|c|c|c|c|c|c|}
\hline \multicolumn{3}{|c|}{ Truck 1} & \multicolumn{3}{|c|}{ Truck 2} \\
\hline No. & $\begin{array}{l}\text { TTF (In } \\
\text { hours) }\end{array}$ & $\begin{array}{l}\text { Workload } \\
\text { (Ton*km) }\end{array}$ & No. & $\begin{array}{l}\text { TTF (In } \\
\text { hours) }\end{array}$ & $\begin{array}{l}\text { Workload } \\
\text { (Ton*km) }\end{array}$ \\
\hline 1 & 18.55 & 2013 & 1 & 225.15 & 21997.8 \\
\hline 2 & 31.15 & 3501.3 & 2 & 255.35 & 26485.8 \\
\hline 3 & 67.05 & 6986.1 & 3 & 109.4 & 10840.5 \\
\hline 4 & 10.4 & 1511.4 & 4 & 52.1 & 6754 \\
\hline 5 & 26.55 & 2963.4 & 5 & 44.4 & 6664.9 \\
\hline 6 & 292.5 & 29494.3 & 6 & 280.11 & 34886.5 \\
\hline 7 & 10.3 & 1217.7 & 7 & 39.2 & 4527.6 \\
\hline 8 & 20.4 & 2992 & 8 & 180.55 & 24619.1 \\
\hline 9 & 101.15 & 10906.5 & 9 & 254.1 & 26753.1 \\
\hline 10 & 85 & 6705.6 & 10 & 22.45 & 2821.5 \\
\hline 11 & 46.05 & 5009.4 & 11 & 45.4 & 6695.7 \\
\hline 12 & 266.29 & 31519.4 & 12 & 252.1 & 28967.4 \\
\hline 13 & 21.3 & 5544 & 13 & 33.5 & 4664 \\
\hline 14 & 35 & 3375.9 & 14 & 9.2 & 3483.7 \\
\hline 15 & 11 & 1230.9 & 15 & 56.25 & 6496.6 \\
\hline 16 & 243.15 & 26690.4 & 16 & 22.15 & 3465 \\
\hline 17 & 120.55 & 13084.5 & 17 & 31.35 & 4048 \\
\hline 18 & 34.1 & 5359.2 & 18 & 44.2 & 12698.4 \\
\hline 19 & 42.05 & 4775.1 & 19 & 169.41 & 34491.6 \\
\hline 20 & 136.35 & 16525.3 & 20 & 20.45 & 2079 \\
\hline 21 & 10.2 & 2420 & 21 & 149.05 & 14813.7 \\
\hline 22 & 19.3 & 10351 & 22 & 326.3 & 47537.6 \\
\hline 23 & 22.15 & 10997.8 & 23 & 61.35 & 11809.6 \\
\hline 24 & 61.15 & 6755.1 & 24 & 33.55 & 4818 \\
\hline 25 & 28.45 & 3177.9 & 25 & 17.55 & 1570.8 \\
\hline 26 & 39.45 & 4492.4 & 26 & 37.35 & 3036 \\
\hline 27 & 29.15 & 3831.3 & 27 & 203.2 & 29823.2 \\
\hline 28 & 2.1 & 653.4 & 28 & 97.55 & 11267.3 \\
\hline 29 & 10.4 & 2051.5 & 29 & 110.25 & 16124.9 \\
\hline 30 & 5 & 1100 & 30 & 45.25 & 6211.7 \\
\hline 31 & 22.05 & 2607 & 31 & 86.45 & 13818.2 \\
\hline 32 & 39.45 & 5643 & 32 & 85.1 & 18590 \\
\hline 33 & 67.21 & 14032.7 & & & \\
\hline 34 & 34.15 & 8911.1 & & & \\
\hline 35 & 94.3 & 13212.1 & & & \\
\hline 36 & 195.4 & 23562 & & & \\
\hline 37 & 32.4 & 5984 & & & \\
\hline 38 & 69.5 & 16434 & & & \\
\hline 39 & 19.25 & 3410 & & & \\
\hline 40 & 56.45 & 10609.5 & & & \\
\hline 41 & 17.25 & 3421 & & & \\
\hline 42 & 89.1 & 15446.2 & & & \\
\hline 43 & 143.4 & 48605.7 & & & \\
\hline 44 & 4.1 & 920.7 & & & \\
\hline 45 & 3.2 & 742.5 & & & \\
\hline 46 & 81.2 & 8434.8 & & & \\
\hline 47 & 87 & 10611.7 & & & \\
\hline 48 & 279.5 & 51966.2 & & & \\
\hline 49 & 10.1 & 1007.6 & & & \\
\hline
\end{tabular}

Table 2. Maximum Likelihood Estimator for $\gamma=1$

\begin{tabular}{||c|c|c|c|c|c||}
\hline \hline Truck & Variable & Parameter & Estimator & $-\ln L$ & Total \\
\hline \multirow{3}{*}{ Truck 1 } & \multirow{2}{*}{ Workload } & $\alpha_{1}$ & 9496 & \multirow{2}{*}{498.5} & \\
\cline { 3 - 4 } & \multirow{2}{*}{ Time } & $\beta_{1}$ & 0.96 & & \multirow{2}{*}{752} \\
\cline { 3 - 4 } & & $\alpha_{2}$ & 63.4 & \multirow{2}{*}{253.5} & \\
\hline \multirow{3}{*}{ Truck 2 } & \multirow{2}{*}{ Workload } & $\alpha_{2}$ & 0.95 & & \\
\cline { 3 - 4 } & \multirow{2}{*}{ Time } & $\beta_{1}$ & 15202 & \multirow{2}{*}{336.8} & \multirow{2}{*}{517.4} \\
\cline { 3 - 4 } & & $\alpha_{2}$ & 112.97 & \multirow{2}{*}{180.6} & \\
\cline { 3 - 4 } & & $\beta_{2}$ & 1.1845 & & \\
\hline
\end{tabular}

$f(t, s)=\left(\alpha_{3} \beta_{1} \beta_{2} t^{\beta_{1}-1} s^{\beta_{2-1}}+\alpha_{2} \alpha_{3} \beta_{1} \beta_{2} t^{\beta_{1}-1} s^{2 \beta_{2}-1}+\alpha_{1} \alpha_{3} \beta_{1} \beta_{2} t^{2 \beta_{1}-1} s^{\beta_{2}-1}+\right.$ $\left.\alpha_{3}^{2} \beta_{1} \beta_{2} t^{2 \beta_{1}-1} s^{2 \beta_{2-1}}\right) \exp \left[-\alpha_{1} t^{\beta_{1}}-\alpha_{2} s^{\beta_{2}}-\alpha_{3} t^{\beta_{1}} s^{\beta_{2}}\right.$

We apply the Bayesian method discussed in Section 3.3 to estimate the parameters. The prior distribution chooses the uniform distribution for the hyper parameters in the Gamma prior distribution. The MCMC method is applied to compute the posterior distribution. After 10,000 iterations, the results converge. The mean of the posterior distribution, which is also the Bayesian estimator of the model, is shown in Table 3.

Table 3. Bayesian Estimator for Linear Bivariate Model

\begin{tabular}{|c|c|c|c|}
\hline \hline Truck & Parameter & Estimator & $-\ln L$ \\
\hline \multirow{4}{*}{ Truck 1 } & $\alpha_{1}$ & $4.61 * 10-4$ & \multirow{2}{*}{7} \\
\cline { 2 - 3 } & $\beta_{1}$ & 0.534 & \multirow{2}{*}{713.4} \\
\cline { 2 - 3 } & $\alpha_{2}$ & 0.01387 & \\
\cline { 2 - 3 } & $\beta_{2}$ & 0.5591 & \\
\cline { 2 - 3 } & $\alpha_{3}$ & 0.001233 & \\
\hline \multirow{4}{*}{ Truck 2 } & $\beta_{1}$ & 0.5853 & \\
\cline { 2 - 3 } & $\alpha_{2}$ & 0.01394 & \\
\cline { 2 - 3 } & $\beta_{2}$ & 0.5893 & \\
\cline { 2 - 4 } & $\alpha_{3}$ & $5.608 * 10-4$ & \\
\hline
\end{tabular}

\subsubsection{Model 3: Exponent bivariate Weibull model}

Similarly to the linear bivariate Weibull model, the paper also let $\mathrm{t}$ in the bi-Weibull denote the calendar time and s denote the work load, Ton $\times \mathrm{kM}$ in Model (8). The prior distribution chooses the Gamma distribution as prior. The results are shown in Table 4.

\subsection{Model selection}

When $\gamma=1$ for Model (8), two variates in the bivariate Weibull model are independent. The bivariate Weibull model is degenerated into two ordinary univariate Weibull models, and the classic parameter estimation for univariate Weibull distribution can be used. Section 3.2 in this paper proposes a likelihood ratio test for the significance of $\gamma=1$. If the hypothesis of $\gamma=1$ is accepted, the simple bivariate model should be chosen. Firstly, we use the maximum likelihood method to estimate the parameter to obtain the likelihood function for Model (8). Table 5 shows the results of maximizing (13) in Section 3.1 by using the constrained optimization method in Matlab for the data from Trucks 1 and 2. The results are close to the Bayesian estimators in Table 4. 
Table 4. Bayesian Estimator for Exponent Bivariate Model

\begin{tabular}{||c|c|c|c||}
\hline Truck & Parameter & Estimator & $-\ln L$ \\
\hline \multirow{4}{*}{ Truck 1 } & $\alpha_{1}$ & 11.210 & \multirow{2}{*}{701.2} \\
\cline { 2 - 3 } & $\beta_{1}$ & 4.526 & \\
\cline { 2 - 3 } & $\alpha_{2}$ & 79.33 & \\
\cline { 2 - 3 } & $\beta_{2}$ & 4.224 & \multirow{2}{*}{480.5} \\
\cline { 2 - 3 } & $\gamma$ & 0.2237 & \\
\hline \multirow{4}{*}{ Truck 2 } & $\alpha_{1}$ & 15760 & \\
\cline { 2 - 3 } & $\beta_{1}$ & 5.861 & \\
\cline { 2 - 3 } & $\alpha_{2}$ & 119.3 & \\
\cline { 2 - 3 } & $\beta_{2}$ & 5.823 & \\
\cline { 2 - 3 } & $\gamma$ & 0.214 & \\
\hline
\end{tabular}

Table 5. Maximum Likelihood Estimator for $\mathrm{g} \neq 1$

\begin{tabular}{||c|c|c|c||}
\hline Truck & Parameter & Estimator & $-\ln L$ \\
\hline \multirow{4}{*}{ Truck 1 } & $\alpha_{1}$ & 10000 & \multirow{2}{*}{} \\
\cline { 2 - 3 } & $\beta_{1}$ & 4.514 & \multirow{2}{*}{700.5} \\
\cline { 2 - 3 } & $\alpha_{2}$ & 70.55 & \multirow{2}{*||}{} \\
\cline { 2 - 3 } & $\beta_{2}$ & 4.224 & \multirow{2}{*}{480.4} \\
\hline \multirow{4}{*}{ Truck 2 } & $\mathrm{g}$ & 0.219 & \\
\cline { 2 - 3 } & $\alpha_{1}$ & 15019 & \\
\cline { 2 - 3 } & $\beta_{1}$ & 6.002 & \\
\cline { 2 - 3 } & $\alpha_{2}$ & 113.9 & \\
\cline { 2 - 3 } & $\beta_{2}$ & 5.9708 & \\
\hline
\end{tabular}

At significant level $\alpha=0.98$, the $\chi^{2}(1)=5.41$. The hypothesis $T$ is $2 \times\left(-\ln \frac{L_{\gamma \neq 1}}{L_{\gamma=1}}\right)=104$ for Truck 1 and 218 for Truck 2. For both trucks, $\chi^{2}(1)=5.41<5.41$. The calculations are shown in Table 6 . Therefore, the hypothesis is rejected for both trucks.

Conclusively, for both trucks, work load and time are not independent. The bivariate Weibull model with $\gamma=1$ is out of consideration for both trucks.

Table 6. Hypothesis Test for $\gamma=1$

\begin{tabular}{|c|c|c|c|c|}
\hline Truck & $\begin{array}{c}\text { Likelihood } \\
\text { of } \gamma=1\end{array}$ & $\begin{array}{c}\text { Likelihood } \\
\text { of } \gamma \neq 1\end{array}$ & $T$ & Result \\
\hline Truck 1 & 752 & 700.5 & 103 & Rejected \\
\hline Truck 2 & 517.4 & 480.4 & 218 & Rejected \\
\hline
\end{tabular}

A more general model selection uses the AIC (Akaike Information Criterion) and BIC (Bayes Information Criterion) [13, 29, 33]. BIC and AIC are defined as:

$$
A I C=-\ln L+2 p \quad \text { and } \quad B I C=-\ln L+p \ln n
$$

where $L$ is the likelihood value, $p$ is the number of parameters, and $n$ is the data size. The model with lower AIC or BIC value is considered to be better. A complex model with more parameters has the potential to be more flexible than the simpler one to fit the data. However, the more complex model tends to have greater uncertainty. The AIC and BIC can balance the complexity and the model uncertainty. The AIC and BIC for the three models are shown in Table 7.

Table 7. BIC and AIC of Models

\begin{tabular}{|c|c|c|c|}
\hline Truck & Model & BIC & AIC \\
\hline \multirow{3}{*}{ Truck 1 } & Simple Model & 1519.6 & 1512 \\
\cline { 2 - 4 } & Model (5) & 1446.3 & 1436.8 \\
\cline { 2 - 4 } & Model (8) & 1421.9 & 1412.4 \\
\hline \multirow{3}{*}{ Truck 2 } & Simple Model & 1048.7 & 1042.8 \\
\cline { 2 - 4 } & Model (5) & 1196.0 & 1188.7 \\
\cline { 2 - 4 } & Model (8) & 978.1 & 970.8 \\
\hline
\end{tabular}

It can be seen from Table 7 that the exponent bivariate Weibull Model (8) has the lowest BIC and AIC values for both trucks and it is therefore considered the best model among the three. The linear bivariate Weibull model has the same number of parameters in the models. However, the BIC and AIC values are higher than the exponent bivariate Weibull. The simple bivariate Weibull shows the worst performance for both trucks. This paper thus selects the exponent bivariate Weibull for both trucks.

\subsection{Analysis using exponent bivariate Weibull}

The model selected is the exponent bivariate Weibull Model (8). The results of parameter estimation by the Bayesian method are elaborated in Table 8. "Std" denotes the standard deviation. The lower and upper bounds of the credible interval are derived from the posterior distribution (22).

Table 8. Bayesian Parameter Estimator for Trucks with Credible Interval

\begin{tabular}{||c|c|c|c|c|c||}
\hline Truck & Parameter & Estimator & Std & Lower & Upper \\
\hline \multirow{4}{*}{ Truck 1 } & $\alpha_{1}$ & 11210 & 929 & 10050 & 13430 \\
\cline { 2 - 6 } & $\beta_{1}$ & 4.526 & 0.5585 & 3.504 & 5.663 \\
\cline { 2 - 6 } & $\alpha_{2}$ & 79.33 & 7.76 & 66.28 & 96.07 \\
\cline { 2 - 6 } & $\beta_{2}$ & 4.224 & 0.5055 & 3.295 & 5.263 \\
\cline { 2 - 6 } & $\gamma$ & 0.2237 & 0.034 & 0.1637 & 0.2972 \\
\hline \multirow{4}{*}{ Truck 2 } & $\alpha_{1}$ & 15760 & 2143 & 11510 & 19660 \\
\cline { 2 - 6 } & $\beta_{1}$ & 5.861 & 0.922 & 4.149 & 7.907 \\
\cline { 2 - 6 } & $\alpha_{2}$ & 119.3 & 16.59 & 88.03 & 153.6 \\
\cline { 2 - 6 } & $\beta_{2}$ & 5.823 & 0.921 & 4.144 & 7.879 \\
\hline \hline
\end{tabular}

Table 8 shows that the $\gamma$ of the data for both trucks is below 0.5 ; the credible bounds of $\gamma$ are far below 1. The results also showed the hypothesis of $\gamma$ should be rejected. This result is consistent with the results from the likelihood ration test described in Table 6.

\subsection{Goodness of fit test}

The assumption of the data fitting the bivariate Weibull model should be validated by the goodness of fit test. The reliability function for Model (8) has the form $R(\Lambda)=\gamma \Lambda^{\gamma-1} \exp \left(-\Lambda^{\gamma}\right)$. This is a univariant Weibull distribution with scale parameter 1 and shape parameter $\gamma$. The proposed goodness of fit test is based on this special structure. Each $\Lambda_{i}$ can be computed from the given data and the estimated 
parameter. This paper proposes a simple goodness of fit test based on the plot. Let $B=\alpha_{1} t^{\beta_{1}}+\alpha_{2} s^{\beta_{2}}$, since:

$$
\ln R(t)=-\mathrm{B}^{\gamma}
$$

The (28) can be converted to a linear function, the linearity can be used to test goodness of fit. The $R(t)$ is approximated by median rank $R(i)=1-(\mathrm{i}-0.3) /(\mathrm{n}+0.4)$. The $\mathrm{B}^{\gamma}$ can be calculated by using the parameters in Table 8. Some of $\mathrm{B}^{\gamma}$ are tabulated in Table 9 for Truck 1 .

The task is to check whether $\ln R(t)$ and $\mathrm{B}^{\gamma}$ is a linear function of form, as $\mathrm{y}=-\mathrm{x}$. If the model fits the data, the data will scatter around the straight line $\mathrm{y}=-\mathrm{x}$. Figure 3 presents the $\ln R(t)$ against $\mathrm{B}^{\gamma}$ for Trucks 1 and 2. For Truck 1, the empirical values (red dots) are around the theoretical values (the blue line in Figure 2). For Truck 2, the empirical data deviate more from the expected value than in the case of Truck 1 . The model is considered unable to fit the data for Truck 2 .

\subsection{Reliability evaluating}

The bivariate Weibull model can be applied to the data from Truck 1. Substitute the estimated parameters into Model (8); the reliability function against calendar time and work load is:

$$
\mathrm{R}(t . s)=\left((t / 11,210)^{4.526}+(s / 79.33)^{4.224}\right)^{0.2237}
$$

Model (29) is plotted in Figure 3 in three dimensions.

Table 10. Reliability for Some Points for Truck 1

\begin{tabular}{||c|c|c|c|c||}
\hline (T.S) & R & Std & Lower & Upper \\
\hline$(20.2000)$ & 0.7165 & 0.05052 & 0.6129 & 0.8097 \\
\hline$(100.10000)$ & 0.2359 & 0.04949 & 0.1491 & 0.342 \\
\hline$(30.10000)$ & 0.3628 & 0.05484 & 0.2604 & 0.4729 \\
\hline$(30.5000)$ & 0.5556 & 0.05654 & 0.4438 & 0.6659 \\
\hline$(300.30000)$ & 0.02118 & 0.01495 & 0.003495 & 0.06009 \\
\hline
\end{tabular}

Table 9. Cumulative Hazard Function and Empirical Reliability

\begin{tabular}{|c|c|c|c|c|c|c|c|c|c|c|c||}
\hline \hline $\mathrm{i}$ & 1 & 2 & 3 & 4 & 5 & 6 & 7 & 8 & 9 & 10 &.. \\
\hline $\boldsymbol{B}^{\prime}$ & 0.058 & 0.068 & 0.084 & 0.10 & 0.146 & 0.152 & 0.1607 & 0.1632 & 0.1934 & 0.2196 &.. \\
\hline $\ln \boldsymbol{R}(\boldsymbol{t})$ & 0.0142 & 0.035 & 0.0562 & 0.078 & 0.10 & 0.123 & 0.146 & 0.170 & 0.194 & 0.219 &.. \\
\hline
\end{tabular}

It is usually of interest to find the reliability for a given time. The reliability and its lower and upper bounds of the credible interval are also computed by the MCMC method described in Section 3.5. Table 10 gives a demonstration of the reliability for some lifetime points.
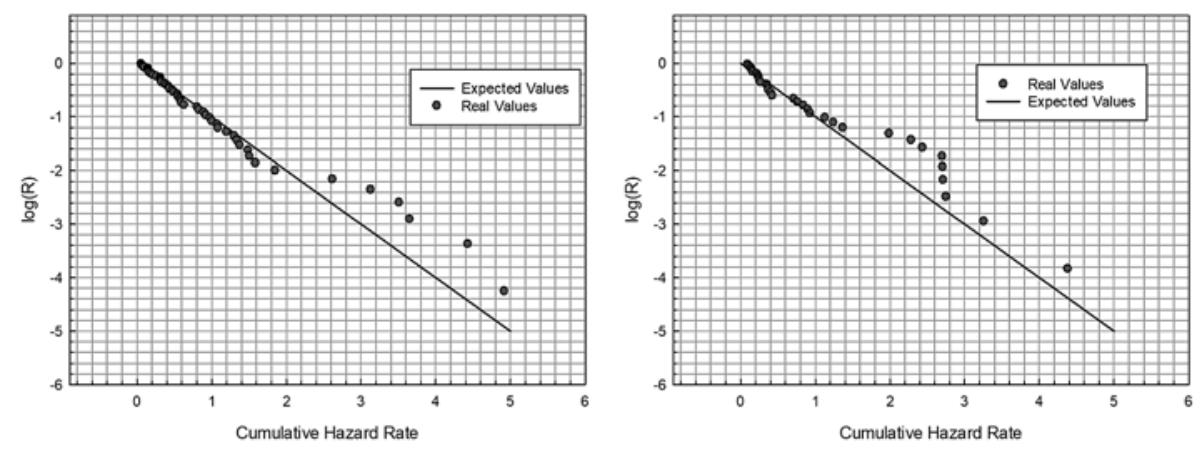

Fig. 2. Goodness of Fit Test for Truck 1 (Left) and Truck 2 (Right)
The reliability function (29) can be further used to schedule the maintenance activities in respect of cost and available resources. This paper omits this, as the maintenance optimization is outside the paper's scope.

\section{Discussion and conclusion}

In the truck data, the work load and the calendar time show significant correlation. The simple bivariate Weibull model is thus not suitable for the data. In this case study, according to the AIC and BIC model selection criteria, the exponent model has the best performance, as it has the lowest AIC and BIC values. Moreover, with reference to our discussion in Section 3, the exponent model is the most general among the three models. The linear bivariate Weibull model only considers the first two orders of the exponent bivariate model. The simple bivariate model does not have the interaction part of the linear bivariate model. The exponent model is more general than the simple model and the linear model.

The reliability of the mining trucks depends on

Fig. 3. Reliability Function of Mining Truck 1 
two dimensions: calendar time and work load. The bivariate Weibull model is proposed to accommodate this two-dimensional life data for reliability modelling. Three bivariate models - simple bivariate Weibull model, linear bivariate Weibull model and the exponent bivariate model - are selected to model the reliability. The exponent model shows the best performance among the three models, and so, in the case study, the reliability model chooses the exponent model. The likelihood ratio test proposed in the paper is used to test whether the correlation of the two dimensions of the data are significant. In the case study, it found the correlation significant. If they are not corre- lated, the simple bivariate is preferred, as the model can be simplified and the traditional parameter estimation method can be used, since each independent variant can be considered as a univariate Weibull distribution. The case study found that the Bayesian method is effective by using the Gamma distribution as prior-distribution. The disadvantage is that obtaining the results requires simulation, which is time-consuming. Future work will focus on the development of a more efficient parameter estimation method.

\section{References}

1. Ahmed A M, Ibrahim N A. Bayesian Estimator for Weibull Distribution with Censored Data using Extension of Jeffrey Prior Information. Procd Soc Behv 2010; 8: 663-669, https://doi.org/10.1016/j.sbspro.2010.12.092.

2. Are N. LCC for Switches and Crossings at the Swedish Railway - A case study. International Journal of Condition Monitoring and Diagnostic Engineering Management 2009; 12: 10-19.

3. Barker K, Baroud H. Proportional hazards models of infrastructure system recovery. Reliab Eng Syst Safe 2014; 124: 201-206, https://doi. org/10.1016/j.ress.2013.12.004.

4. Barlow R E, Proschan F, Hunter L C. Mathematical theory of reliability. Philadelphia: SIAM, 1996, https://doi. org/10.1137/1.9781611971194.

5. Berger J O, Sun D C. Bayesian-Analysis for the Poly-Weibull Distribution. J Am Stat Assoc 1993; 88: 1412-1418, https://doi. org/10.1080/01621459.1993.10476426.

6. D.Hanagal D. A multivariate Weibull distribution. Economic Quality Control 1996; 11: 193-200.

7. Drury M R, Walker E V, Wightman DW, Bendell A. Proportional Hazards Modeling in the Analysis of Computer-Systems Reliability. Reliab Eng Syst Safe 1988; 21: 197-214, https://doi.org/10.1016/0951-8320(88)90121-4.

8. Genest C, Rivest L P. Statistical-Inference Procedures for Bivariate Archimedean Copulas. J Am Stat Assoc 1993; 88: 1034-1043, https://doi. org/10.1080/01621459.1993.10476372.

9. Hanagal D A. Bivariate Weibull regression model based on censored samples. Stat Pap 2006; 47: 137-147, https://doi.org/10.1007/s00362005-0277-4

10. Hougaard P. A Class of Multivariate Failure Time Distributions. Biometrika 1986; 73: 671-678, https://doi.org/10.2307/2336531.

11. Hougaard P. Modeling Multivariate Survival. Scand J Stat 1987; 14: 291-304.

12. Jack N, Iskandar B P, Murthy D N P. A repair-replace strategy based on usage rate for items sold with a two-dimensional warranty. Reliab Eng Syst Safe 2009; 94: 611-617, https://doi.org/10.1016/j.ress.2008.06.019.

13. Kim Y, Park J, Jung W, Jang I, Seong P H. A statistical approach to estimating effects of performance shaping factors on human error probabilities of soft controls. Reliab Eng Syst Safe 2015; 142: 378-387, https://doi.org/10.1016/j.ress.2015.06.004.

14. Kumar D, Klefsjo B. Proportional Hazards Model - a Review. Reliab Eng Syst Safe 1994; 44: 177-188, https://doi.org/10.1016/09518320(94)90010-8.

15. Kumar D, Westberg U. Proportional hazards modeling of time-dependent covariates using linear regression: A case study. IEEE T Reliab 1996; 45: 386-392, https://doi.org/10.1109/24.536990.

16. Kundu D, Gupta A K. Bayes estimation for the Marshall-Olkin bivariate Weibull distribution. Comput Stat Data An 2013; 57: 271-281, https://doi.org/10.1016/j.csda.2012.06.002.

17. Lee L. Multivariate Distributions Having Weibull Properties. J Multivariate Anal 1979; 9: 267-277, https://doi.org/10.1016/0047259X(79)90084-8.

18. Leira B J. A comparison of some multivariate weibull distributions. Proceedings of the ASME 2010 29th Internatinal conference on Ocean, offshore and arctic Engineering, 2010, Shanghai, China, https://doi.org/10.1115/OMAE2010-20678.

19. Lu J-C. Bayes Paramter Estimation for the Bivariate Weibull Model of Marshall-Olkin for censored data. Ieee T Reliab 1992; 41: 608-615, https://doi.org/10.1109/24.249597.

20. Lu J C, Bhattacharyya G K. Some New Constructions of Bivariate Weibull Models. Ann I Stat Math 1990; 42: 543-559, https://doi. org/10.1007/BF00049307.

21. Lunn D, Jackson C, Best N, Thomas A, Spiegelhalter D. The BUGS book : a practical introduction to Bayesian analysis. London: CRC Press, 2013.

22. Lynch S M. Introduction to applied Bayesian statistics and estimation for social scientists. New York: Springer, 2007, https://doi. org/10.1007/978-0-387-71265-9.

23. Marshall A W, Olkin I. A Multivariate Exponential Distribution. J Am Stat Assoc 1967; 62: 30-44, https://doi. org/10.1080/01621459.1967.10482885.

24. Meeker WQ, Escobar LA (1998) Statistical methods for reliability data. New York: Wiley,1998.

25. Mostafa B, Celeux G. Bayesian estimation of a Weibull distribution in a highly censored and small sample setting. Institut National De Recherche En Informatque Et Automatique. 1996.

26. Murthy D N P, Xie M, Jiang R. Weibull models. J. New Jersey: Wiley, 2004.

27. Nelsen RB. Copulas and quasi-copulas: An introduction to their properties and applications. Logical, Algebraic, Analytic, and Probabilistic Aspects of Triangular Norms 2005; 391-413.

28. Hryniewicz O, Kaczmarek K, Nowak P. Bayes statistical decisions with random fuzzy data - an application for the Weibull distribution. Eksploatacja i Niezawodnosc - Maintenance and Reliability 2015; 17 (4): 610-616, http://dx.doi.org/10.17531/ein.2015.4.18.

29. Posada D, Buckley T R. Model selection and model averaging in phylogenetics: Advantages of akaike information criterion and Bayesian 
approaches over likelihood ratio tests. Syst Biol 2004; 53: 793-808, https://doi.org/10.1080/10635150490522304.

30. Roy D. Classification of Life Distributions in Multivariate Models. IEEE T Reliab 1994; 43: 445-445, https://doi.org/10.1109/24.294995.

31. Roy D, Mukherjee S P. Multivariate extensions of univariate life distributions. J Multivariate Anal 1998; 67: 72-79, https://doi.org/10.1006/ jmva.1998.1754.

32. Ryu K. An extension of Marshall and Olkin multivariate exponential distribution. Journal of American Statistical Association 1993; 88: 1458-1465, https://doi.org/10.1080/01621459.1993.10476434

33. Sarhan A M, Hamilton D C, Smith B. Statistical analysis of competing risks models. Reliab Eng Syst Safe 2010; 95: 953-962, https://doi. org/10.1016/j.ress.2010.04.006.

34. Wen M-J, Lee C K. A. Multivariate Weibull Distribution. Pakistan Journal of Statistical operation research 2009; 5: 55-66.

Yuan FUQING
Abbas BARABADI
Lu JINMEI
Department of Engineering and Safety
University of Tromsø
N-9037 Tromsø, Norway
E-Mails: yuan.fuqing@uit.no, abbas.b.abadi@uit.no,
jinmei.lu@uit.no

